\title{
Structural Response to Blast Loading: The Effects of Corrosion on Reinforced Concrete Structures
}

\author{
Hakan Yalciner \\ Civil Engineering Department, Erzincan University, Turkey \\ Correspondence should be addressed to Hakan Yalciner; hakan.yalciner@emu.edu.tr
}

Received 1 July 2013; Accepted 1 January 2014; Published 2 June 2014

Academic Editor: Nuno Maia

Copyright (C) 2014 Hakan Yalciner. This is an open access article distributed under the Creative Commons Attribution License, which permits unrestricted use, distribution, and reproduction in any medium, provided the original work is properly cited.

Structural blast design has become a necessary part of the design with increasing terrorist attacks. Terrorist attacks are not the one to make the structures important against blast loading where other explosions such as high gas explosions also take an important place in structural safety. The main objective of this study was to verify the structural performance levels under the impact of different blast loading scenarios. The blast loads were represented by using triangular pulse for single degree of freedom system. The effect of blast load on both corroded and uncorroded reinforced concrete buildings was examined for different explosion distances. Modified plastic hinge properties were used to ensure the effects of corrosion. The results indicated that explosion distance and concrete strength were key parameters to define the performance of the structures against blast loading.

\section{Introduction}

Most of the design codes consider essentially the seismic, wind, rain, and snow loads. Blast loads have different place in engineering when they are compared with other loads. Even the fundamentals of blast and seismic design depend on dynamic behaviour and energy dissipation approaches; the design of blast and the response of the structures against blast loads are extremely different than other well-known loads. Unlike seismic and wind loads, blast loads have a short duration, generally in milliseconds (ms). With increasing terrorist attacks on military buildings, blast design has kept its popularity to develop new design codes. From military buildings, blast design has started to be adopted for residential buildings to resist the gas explosions in huge and closed areas. Thus, the first blast design code has been developed by FEMA 427 [1]. On March 20, 2003, the United States attacked Iraq. Over 4,000 US soldiers died in that war. Most of those deaths occurred with suicide truck bomb that exploded in front of military buildings. Figure 1 shows a typical effect of blast load on Canal Hotel in Baghdad, Iraq, in 2003. The building was heavily damaged by using trinitrotoluene (TNT) which exploded at a nearby distance.

If an explosion distance is pretty close and the building walls are not designed by shear walls, the blast also affects the interior side of the buildings. Such an explosion was done by couple car bomb attacks in central Baghdad in 2007. Fiftynine people died as a result of explosions. Twenty people out of fifty-nine were located inside of the building. For an explosion outside a building, the exterior envelope (i.e., wall, reinforced concrete members, and glass) is the critical line of defence that separates the people, operations, and contents inside the building from the air-blast effects outside the building [2]. Unfortunately, most of the buildings in Iraq were ill-suited to resist the blast loads which could have saved the people that were located inside of the buildings. Not only the reinforced concrete buildings but also bridges, railways, and roads are under the blast risk. Exploded blast load on major bridges in Baghdad caused collapse to the whole truss steel frames and concrete asphalt. Within a short period of explosion, connections of the steel bars were melded with crushed concrete. The released potential energy with blast load is much more effective on steel structures when it is compared with reinforced concrete buildings since steel structures provide little resistance to thermal energy. While the blast load causes the steel structures to melt, it turns the concrete into sand and dust by exceeding yield strength of concrete. At this point not only the amount of the blast load but also the pressure of the wave to the surface of concrete and explosion distance take an important place for 


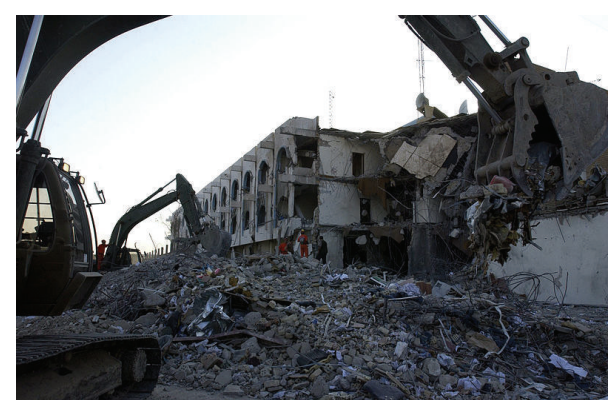

FIGURE 1: Destroyed reinforced concrete building by blast load [15].

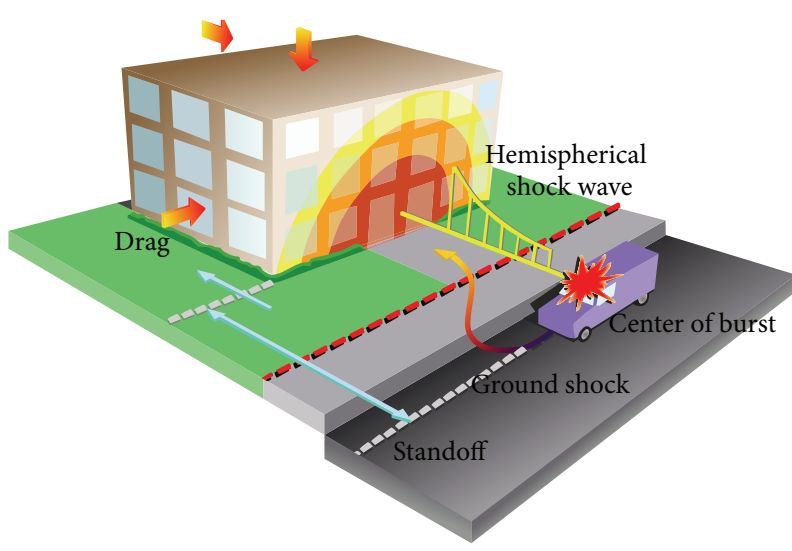

Overpressure

Reflected pressure

Perimeter protection

(fence, guards, and barriers)

FIgURE 2: Schematic of a blast load [4].

structures. When a response of a building from blast load is considered, natural period of vibration of the structure is the vital parameter for a given explosion. Ductile elements made of steel and reinforced concrete absorb a lot of strain energy [3]. The effects of blast on reinforced concrete and steel structures have been widely studied by many researchers. To the knowledge of the author, the effects of corrosion with blast loads on reinforced concrete buildings have not been studied. Therefore, in this study, different blast load scenarios were performed for uncorroded and corroded reinforced concrete buildings to investigate the effect of blast loads with corrosion. Performance levels of the reinforced concrete buildings were obtained under the effect of blast loads. The impacts of the blast waves on the surface of the structural members were simulated.

\section{Blast and Loadings}

Blast can be defined as a rapid phase of a created pressure by a sudden release of energy. This energy provides a blast wave in different shapes. The general generated blast wave has been formed in a hemispherical form away from the blast site as shown in Figure 2.
In this study, the peak static overpressure was calculated based on the model developed by Smith and Hetherington [4]:

$$
\begin{aligned}
& \text { for } P_{s}>10 \text { bar } P_{s}=\frac{6.7}{Z^{3}}+1 \\
& \text { for } 0.1<P_{s}<10 \text { bar } P_{s}=\frac{0.975}{Z}+\frac{1.455}{Z^{2}}+\frac{5.85}{Z^{3}},
\end{aligned}
$$

where $Z$ is the scaled distance $\left(\mathrm{ft} / \mathrm{lb}^{1 / 3}\right)$ and it can be calculated by the following equation. In (2) $R$ and $W$ denote the explosion distance ( $\mathrm{ft}$ ) and the explosives weight (lb) in TNT, respectively:

$$
Z=\frac{R}{W^{1 / 3}} .
$$

Idealized pressure-time history of a blast load and comparison between free-field, or side-on, and reflected pressuretime histories are shown in Figure 3. In Figure 3(a), $P_{o}$ is the ambient pressure, $P_{\text {so }}$ is the peak positive side-on overpressure, $P_{\text {so }}^{-}$is the peak negative side-on overpressure, $P_{s}(t)$ is the time varying positive overpressure, $P_{s}^{-}(t)$ is the time varying negative overpressure, $P_{r}$ is the peak reflected overpressure, $I_{s}$ is the positive-phase-specific impulse (the integration of the positive phase pressure-time history), and $i_{s}^{-}$is the negative-phase-specific impulse (the integration of the negative phase pressure-time history).

The velocity of a wave $\left(U_{s}\right)$ and the maximum pressure were calculated based on the model proposed by Smith and Hetherington [4]. Consider

$$
U_{s}=\sqrt{\frac{6 P_{s}+7 P_{o}}{7 P_{o}}} \cdot a_{o},
$$

$$
q_{s}=\frac{5 P_{s}^{2}}{2\left(P_{s}+7 P_{o}\right)},
$$

where $a_{o}$ is the ambient air pressure ahead of wave, $\gamma$ is the specific heat ratio, and $\rho$ is the density of air. The reflected pressure, $P_{r}$, was then calculated by following equations:

$$
\begin{gathered}
P_{r}=2 P_{s}+(\gamma+1) q_{s}, \\
q_{s}=\frac{1}{2} \rho_{s} u_{s}^{2}, \\
u_{s}=\frac{a_{o} \cdot P_{s}}{\gamma P_{o}}\left[1+\left[\frac{\gamma+1}{2 \gamma}\right] \cdot \frac{P_{s}}{P_{o}}\right]^{-1 / 2}, \\
P_{r}=2 P_{s}\left[\frac{7 P_{o}+4 P_{s}}{7 P_{o}+P_{s}}\right] .
\end{gathered}
$$

In this study, four different explosion distances (i.e., $6 \mathrm{~m}$, $12 \mathrm{~m}, 18 \mathrm{~m}$, and $24 \mathrm{~m}$ ) were defined with having the same amount of $150 \mathrm{~kg}$ TNT. The mass specific energy for TNT was equal to $4520 \mathrm{~kJ} / \mathrm{kg}$.

\section{Material Modelling}

In order to perform the blast load with combined corrosion effects, stress and strain relationships of concrete and reinforcement bars were defined by user. In this study we used the 


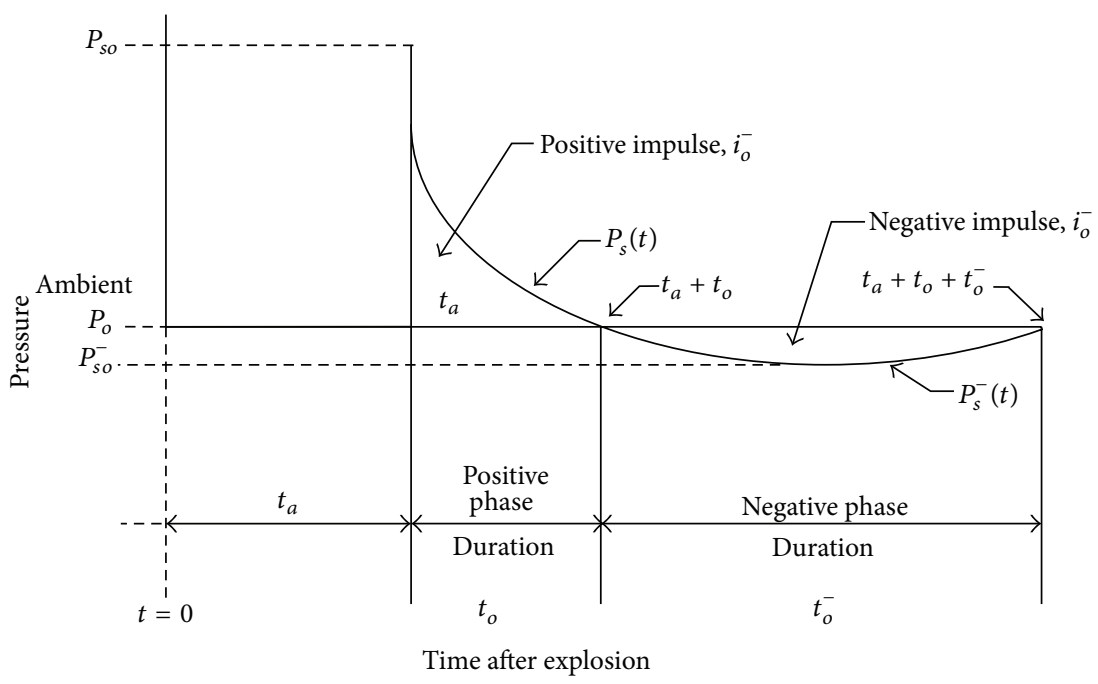

(a)

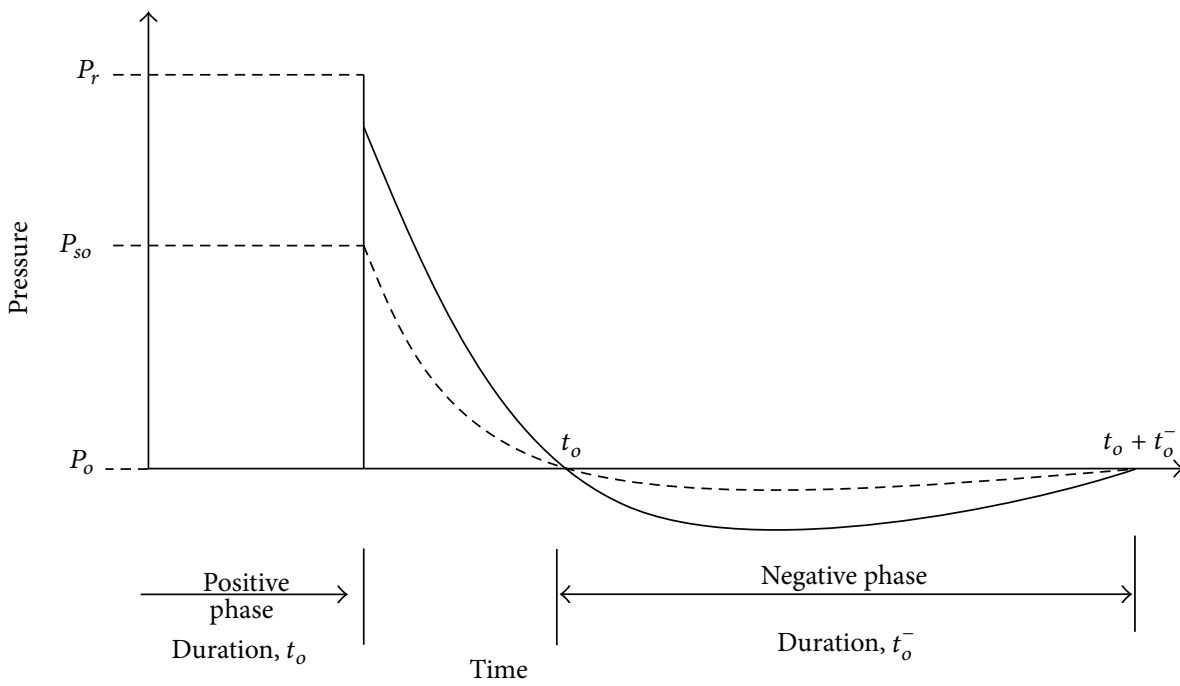

(b)

Figure 3: (a) Blast wave pressure-time graph. (b) Blast load and comparison [4].

model with more than 30 years developed by Kent and Park [5] to model the stress and strain relationships of concrete. Basically, this model by Kent and Park [5] has two segments. For the first segment (A-B), the curve reaches maximum stress level which is equal to 0.002 . After reaching maximum stress, two different other segments occur (B-C, B-D) where two straight lines indicate different behaviour of concrete for confined and unconfined concrete. Figure 4(a) shows Kent and Park [5] model for the stress-strain relationship of reinforced concrete sections. In this study Mander's [6] model was used for the modelling of stress-strain relationship of reinforcement bars. Mander [6] proposed a model which can be used for both softer and harder steel. The model includes linear elastic region up to yield, elastic-perfect-plastic region, and strain hardening region. Mander's model [6] controls both strength and ductility where descending branch of the curve that first branch increase linearly until yield point and then the curve continues as constant. Figure 4(b) shows the model proposed by Mander [6] for stress and strain relationships of reinforcement bars.

The steel and concrete classes were selected as S420 (420 MPa) and C40 (40 MPa), respectively. Elastic modulus of concrete $\left(E_{c}=3250 \sqrt{f_{c}^{\prime}}+14000 \mathrm{MPa}\right)$ was calculated according to Turkish standards 500 [7], and the elastic modulus of steel $\left(E_{s}\right)$ was taken as $200,000 \mathrm{MPa}$. A corrosion rate of $0.40 \mu \mathrm{A} / \mathrm{cm}^{2}$ was assumed to be used in analyses. A corrosion rate in $\mathrm{mm} /$ year was converted to $\mu \mathrm{A} / \mathrm{cm}^{2}$ by considering that $1 \mu \mathrm{A} / \mathrm{cm}^{2}$ is equal to $0.0116 \mathrm{~mm} /$ year. Three major effects (i.e., loss in cross-sectional area of reinforcement bars, reduction in concrete strength, and bond-slip relationships) of corrosion were taken into account. Reduction in concrete strength was calculated based on the model developed by Yalciner et al. [8]. The model developed by Yalciner et al. 


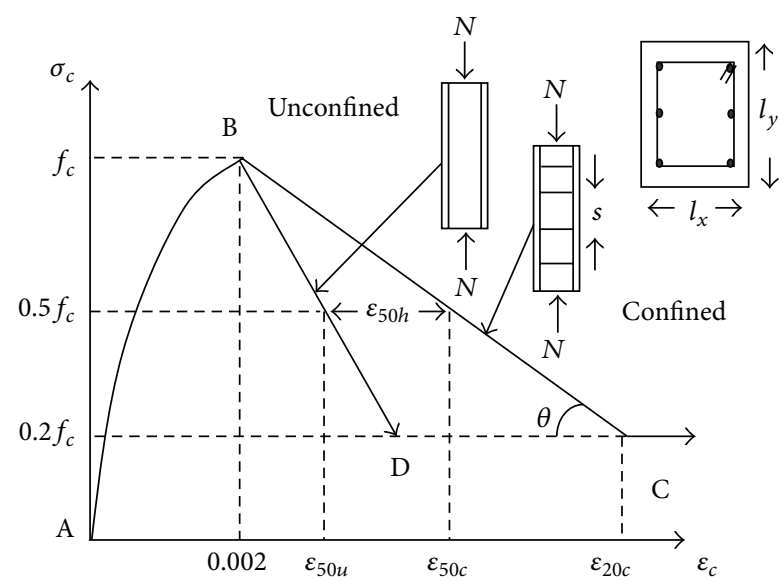

(a)

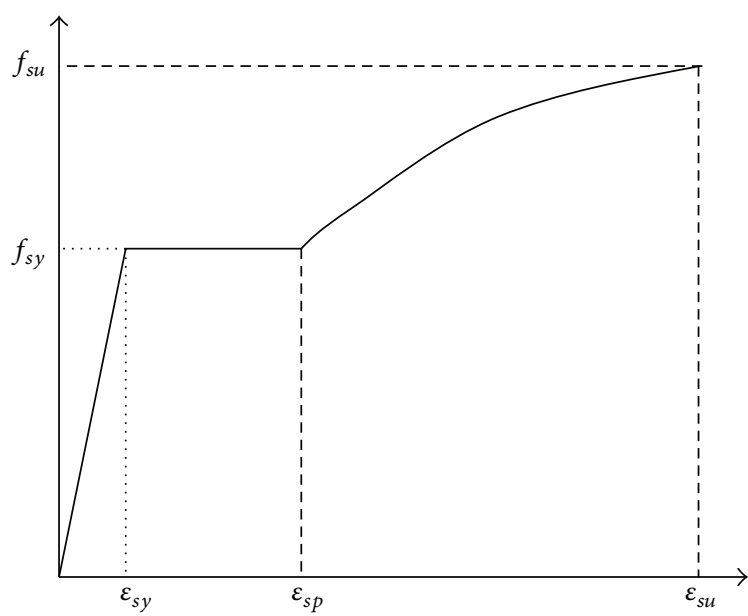

(b)

FIGURE 4: (a) Stress-strain relation of reinforced concrete [5]. (b) Stress-strain relation of steel bars [6].

[8] provides calculation of the reduction in concrete strength as a function of corrosion rate or mass loss. The volume of corrosion rust is generally 2 to 4 times larger than the volume of original reinforcement [9]. The porous zone around the reinforcing bars is filled with this corrosion product which results in internal pressure on the surrounding concrete. As a consequence of volumetric expansion inside of concrete, the concrete strengths reduce as a function of corrosion rate which occurs due to increased width. The model developed by Yalciner et al. [8] to calculate the increased width of the structural members due to corrosion is given in

$$
\begin{aligned}
b_{f} & -b_{0} \\
& =n_{\text {bars }}\left(\frac{4 \pi d_{s}(t)}{\left(1-v_{c}\right) /(a / b)^{\sqrt{\alpha}}+\left(1+v_{c}\right)(b / a)^{\sqrt{\alpha}}}-\frac{2 \pi b f_{t}}{E_{\mathrm{ef}}}\right) .
\end{aligned}
$$

In (5), $b_{f}$ is the width increased by corrosion cracking, $b_{0}$ is the section width in the virgin state, $n_{\text {bars }}$ is the number of the bars in the top layer (compressed bars), $d_{s}(t)$ is the thickness of corrosion product form, $v_{c}$ is the Poisson's ratio of concrete, $f_{t}$ is the tensile strength of concrete, $E_{\text {ef }}$ is the effective elastic modulus of concrete $\left(a=\left(d_{b}+2 d_{0}\right) / 2\right), d_{b}$ is the diameter of reinforcement bars, $d_{0}$ is the thickness of the annular layer of concrete pores, $b$ is the outer radii of the of the thick-wall cylinder $(b=S / 2), S$ is the rebar spacing, and $c_{5}$ and $c_{6}$ are boundary conditions as proposed by Li et al. [10]. Once the corrosion rate is known, the reduction in concrete strength can be predicted by using the model developed by Yalciner et al. [8]. Yalciner et al. [11] in another study also developed a corrosion model to predict the ultimate bond strength of uncorroded and corroded reinforcement bars as a function of three different concrete cover depths and two different concrete strength levels for different given corrosion levels by using accelerated corrosion method and performed pull-out tests. In this study to calculate the ultimate bond strength of uncorroded structural members, the developed model by Yalciner et al. [11] was used by given (6). In (6), $f_{c}^{\prime}$ is the concrete compressive strength, $c$ is the concrete cover depth, and $D$ is the diameter of a steel bar:

$$
\tau_{b u}=-2.7143+0.3621 f_{c}^{\prime}+2.3296\left(\frac{c}{D}\right)(\mathrm{MPa}) .
$$

In order to calculate and predict the ultimate bond strength of corroded structural members, the following model developed by Yalciner et al. [11] was used. In (7) developed bond strength model by Yalciner et al. [11] considers the limits of corrosion levels for the ascending branch when cover to diameter ratios are equal and greater than two. Consider

$$
\begin{gathered}
\text { if } \frac{c}{D} \geq 2, \quad\left\{\begin{array}{l}
0 \leq C_{L} \leq 1.4 \quad \text { for } f_{c}^{\prime}=23 \mathrm{MPa} \\
0 \leq C_{L} \leq 0.68 \quad \text { for } f_{c}^{\prime}=51 \mathrm{MPa}
\end{array}\right. \\
\tau_{b u}=e^{\left(0.01572 f_{c}^{\prime}+0.22957(c / D)+0.13946 C_{L}+1.75913\right)}(\mathrm{MPa}) .
\end{gathered}
$$

Calculated bond strengths of structural member were used to predict the slippage of reinforcement bars. For doing this a well-known slip model developed by Alsiwat and Saatcioglu [12] was used. In the model developed by Alsiwat and Saatcioglu [12], the development length was divided into four regions, based on the state of the steel stressstrain relationship (i.e., an elastic region, a yield plateau, a strain hardening region, and a pull-out cone region). Alsiwat and Saatcioglu [12] suggested thatonce extension of a reinforcement bar is calculated, slip rotation can be calculated by using moment-curvature relationships given by

$$
\theta_{s}=\frac{\delta_{\mathrm{ext}}}{d-c},
$$

where $d$ is the section depth, $c$ is the neutral axis of assessed section, and $\delta_{\text {ext }}$ is the extension of a bar. Calculated reduction in concrete strength (see (5)), loss in cross-sectional area, predicted bond strength (see (6) and (7)), and slip rotations (see (8)) were used to modify the moment-curvature relationships of defined structural member. 


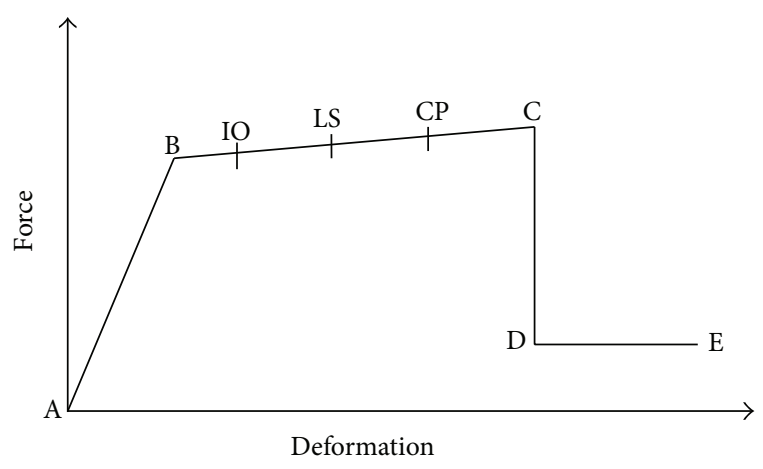

FIGURE 5: Force-deformation relationship of a plastic hinge.

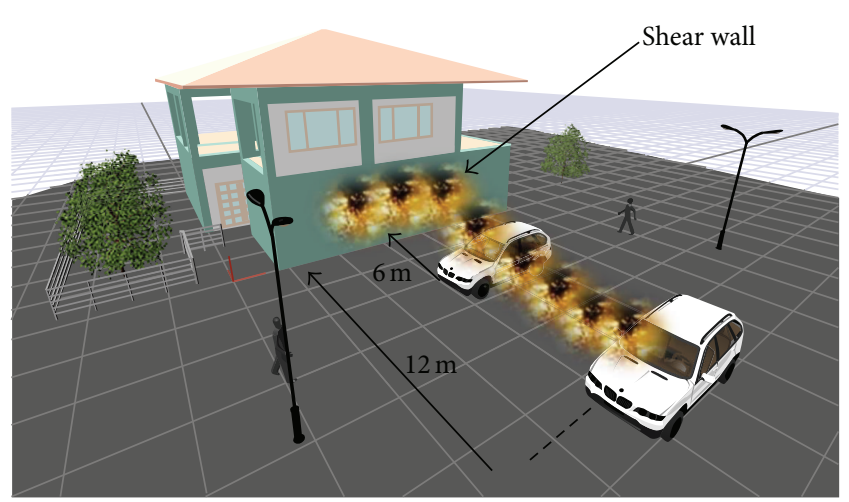

FIgURE 6: Modelled reinforced concrete building.

\section{Blast Analyses and Results}

Calculated moment-curvature relationships were used to define the force-deformation relationships. Forcedeformation behaviour was defined by using a described standard by FEMA-356 [13]. Figure 5 shows forcedeformation relationships to define the behaviour of a plastic hinge by FEMA-356 [13]. On Figure 5 labelled A, B, $\mathrm{C}, \mathrm{D}$ define force-deformation behaviour which is detail explained by FEMA-356 [13].

The lengths of the plastic hinges $\left(L_{p}\right)$ were calculated according to Park and Paulay [14] by

$$
L_{p}=0.5 H \text {, }
$$

where $H$ is the related section depth of element. As mentioned earlier, four different explosion distances (i.e., $6 \mathrm{~m}$, $12 \mathrm{~m}, 18 \mathrm{~m}$, and $24 \mathrm{~m}$ ) were defined. For this purpose a reinforced concrete building was modelled. The results of the blast effect with combined corrosion damage on building were discussed for designed shear wall as shown in Figure 6.

The first explosion was done with an explosion distance of $6 \mathrm{~m}$ and continued with other distances. The results clearly indicated that effect of blast regarding the damage of reinforced concrete building and the resistance of concrete is much more important than the reinforcement bars. At this point, the role of the reinforcement bars on concrete was corrosion. If the reinforcement bars were corroded, with increased cracks within the concrete as a function

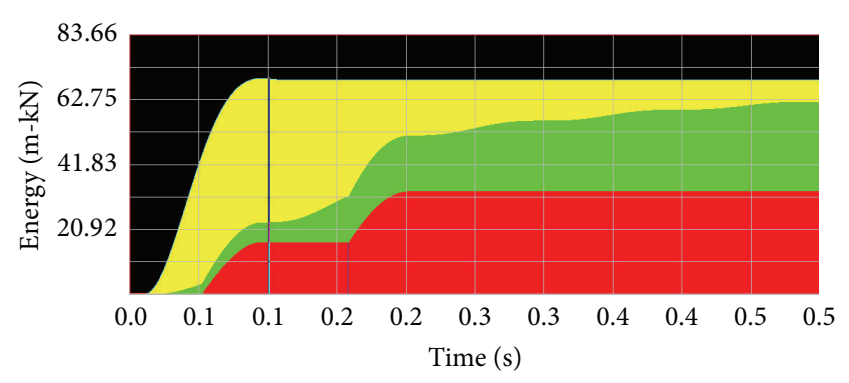

Energy contribution as \% of total

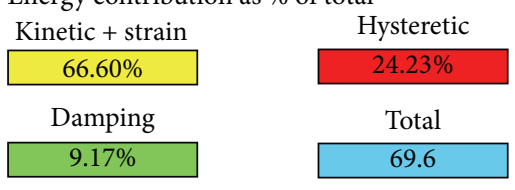

(a)

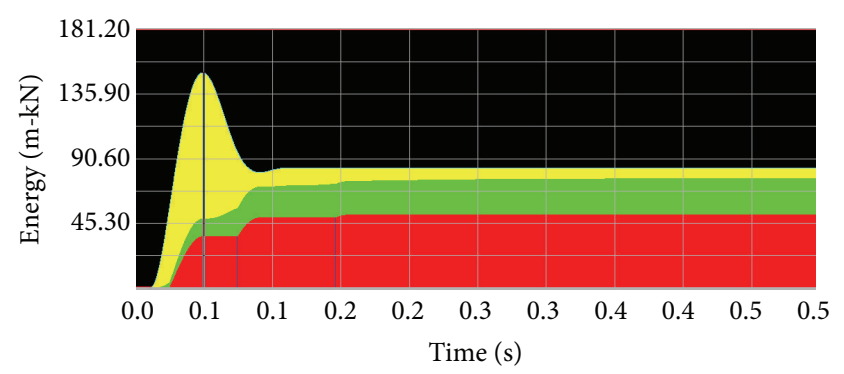

Energy contribution as \% of total

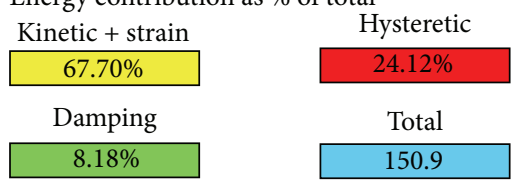

(b)

FIGURE 7: Blast load with a 6 m explosion: (a) uncorroded shear wall and (b) corroded shear wall.

of corrosion rate caused to increase the effect of the blast load. After the first explosion, the results of the energy contributions of the kinetic + strain, damping, and hysteretic energies as well as the total energy are shown in Figure 7. In Figure 7 the hysteretic energy was an indication of structural damage resulting from the application of the blast load.

As shown in Figure 7(a), structural damage resulting from the application of the blast load was less when it was compared with corroded shear wall due to crack width of concrete caused by corrosion. The results of exploded TNT for $18 \mathrm{~m}$ and $24 \mathrm{~m}$ for both uncorroded and corroded cases were given in Figures 8 and 9, respectively.

In Figure 8, as it was expected, with increased explosion distance, damage to structure was reduced. Moreover, percentage contribution of the hysteretic energy to the total energy was higher for corroded shear wall. The recorded relative percentages of hysteretic energy of uncorroded and corroded concrete members were $3.42 \%$ and $7.00 \%$, respectively. These percentages were reduced to zero percentages with an increased explosion distance by $24 \mathrm{~m}$ at the same period of $0.15 \mathrm{~ms}$ (see Figure 9). Structural damage resulting from the application of the blast load having $0.2 \mathrm{~ms}$ was $1.5 \%$ 


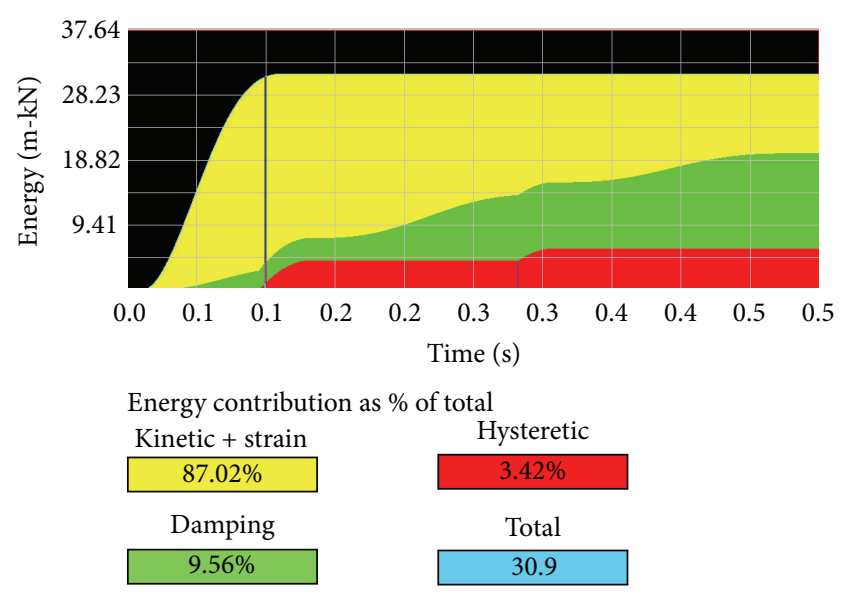

(a)

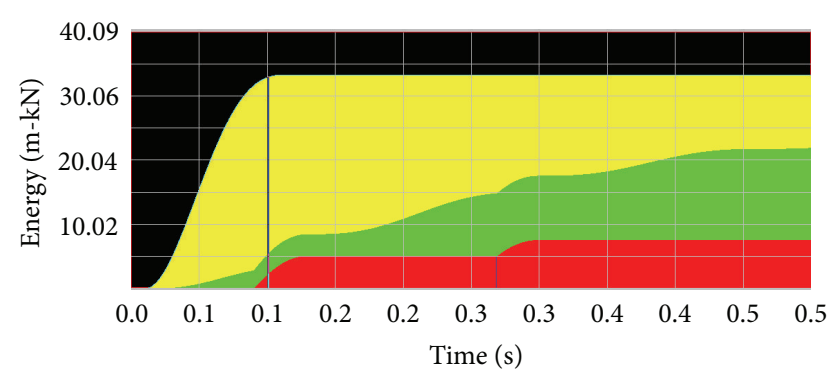

Energy contribution as \% of total

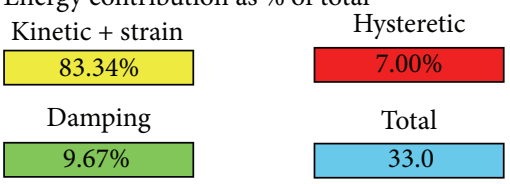

(b)

FIGURE 8: Blast load with $18 \mathrm{~m}$ explosion distance: (a) uncorroded shear wall and (b) corroded shear wall.

and 2.38\% for uncorroded and corroded concrete members, respectively. When two different explosion distances were compared, the recorded $24.23 \%$ of relative percentage of hysteretic energy was reduced to zero percentage with increased explosion distance from $6 \mathrm{~m}$ to $24 \mathrm{~m}$ within $0.10 \mathrm{~ms}$.

\section{Conclusion}

The effects of blast load on corroded and uncorroded reinforced concrete buildings were studied for different explosion distances. The results clearly indicated that structural damage was reduced with increased explosion distances by depending on amount of TNT that was used in current study. Performed blast loads and obtained results showed that effect of corrosion did not play a major role in the percentage contribution of the hysteretic energy to the total energy by reduction in cross-sectional area of reinforcement bars. Increased crack width of concrete due to corrosion played a major role in the case of corroded structural member. Reduction in cross-sectional area of reinforcement bars directly caused premature yielding of reinforcement bars. Thus, a few amount of energy absorption has been lost during blast load. Since the

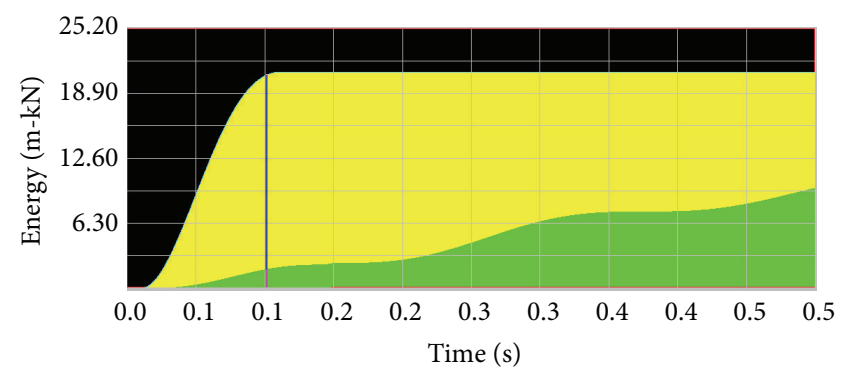

Energy contribution as \% of total

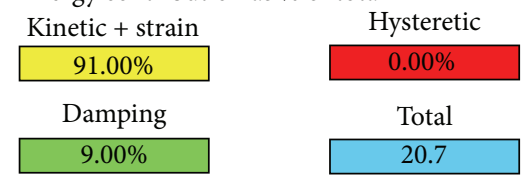

(a)

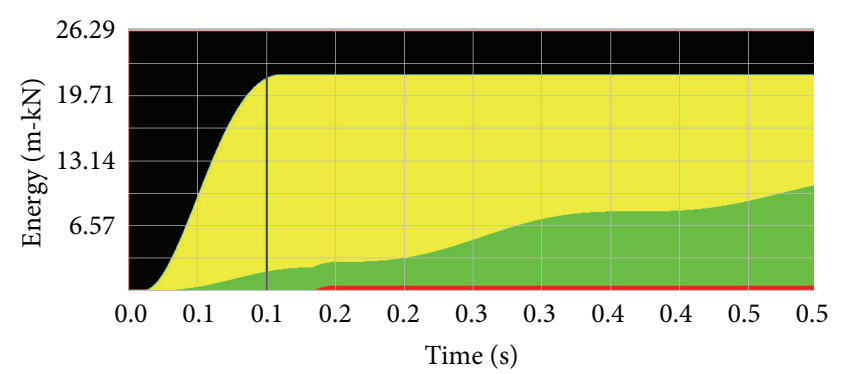

Energy contribution as \% of total

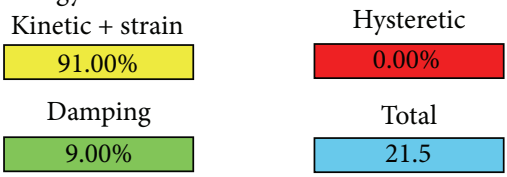

(b)

FIGURE 9: Blast load with a $24 \mathrm{~m}$ of explosion distance: (a) uncorroded shear wall and (b) corroded shear wall.

yield and compressive strength of concrete were vital parameters, slippage of reinforcement bars due to corrosion against blast load with a very close explosion distance measured in milliseconds did not influence the performance of the structure. It is believed that the methodology described here will be a guideline for further studies and novel investigations. Therefore, buckling problems and particularly irregularities of buildings under the effect of blast loads do require further studies. The lessons learned from terrorist events in the recent past could guide us in the design and in the risk assessment of buildings considering their vulnerability to blast loading.

\section{Conflict of Interests}

The author declares that there is no conflict of interests regarding the publication of this paper.

\section{References}

[1] Federal Emergency Management Agency (FEMA), Risk Management Series Primer for Design of Commercial Buildings to Mitigate Terrorist Attacks, FEMA 427, 2003. 
[2] D. O. Dusenberry, Ed., Handbook of Blast Resistant Design of Buildings, John Wiley \& Sons, 2010.

[3] "Design of buildings to optimize resistance to blast loading," in Blast Effects on Buildings, G. C. Mays and P. D. Smith, Eds., 1995.

[4] P. D. Smith and J. G. Hetherington, Blast and Ballistic Loading of Structures, 2nd edition, 1994.

[5] D. C. Kent and R. Park, "Flexural members with confined concrete," Journal of Structural Division, vol. 97, no. 7, pp. 19691990, 1997.

[6] J. B. Mander, Seismic design of bridge piers [Ph.D. thesis], University of Canterbury, Canterbury, New Zealand, 1984.

[7] Turkish Standards Institute, "Requirements for design and construction of reinforced concrete structures," Tech. Rep. TS500, Turkish Standards Institute, Ankara, Turkey, 2000.

[8] H. Yalciner, S. Sensoy, and O. Eren, "Time-dependent seismic performance assessment of a single-degree-of-freedom frame subject to corrosion," Engineering Failure Analysis, vol. 19, no. 1, pp. 109-122, 2012.

[9] Z. P. Bazant, "Physical model for steel corrosion in concrete sea structures-application," ASCE Journal of the Structure Division, vol. 105, no. 6, pp. 1155-1166, 1979.

[10] C. Q. Li, J. J. Zheng, W. Lawanwisut, and R. E. Melchers, "Concrete delamination caused by steel reinforcement corrosion," Journal of Materials in Civil Engineering, vol. 19, no. 7, pp. 591600, 2007.

[11] H. Yalciner, O. Eren, and S. Sensoy, "An experimental study on the bond strength between reinforcement bars and concrete as a function of concrete cover, strength and corrosion level," Cement and Concrete Research, vol. 42, no. 5, pp. 643-655, 2012.

[12] J. M. Alsiwat and M. Saatcioglu, "Reinforcement anchorage slip under monotonic loading," ASCE Journal of Structural Engineering, vol. 118, no. 9, pp. 2421-2438, 1992.

[13] Federal Emergency Management Agency, Pre-Standard and Commentary for the Seismic Rehabilitation of Buildings, The American Society of Civil Engineers for the Federal Emergency Management Agency (FEMA), Washington, DC, USA, 2000, Publications no. 356.

[14] R. Park and T. Paulay, Reinforced Concrete Structures, John Wiley \& Sons, New York, NY, USA, 1975.

[15] BBC news, 2012, http://www.bbc.co.uk/news/world-middleeast-18422636. 

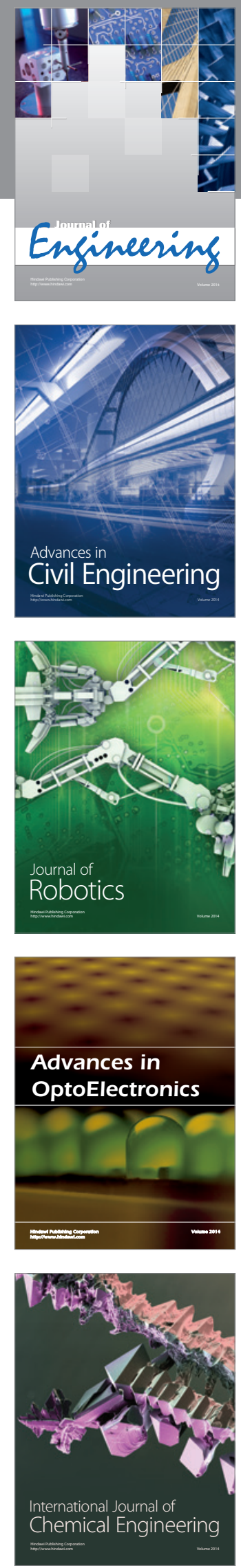

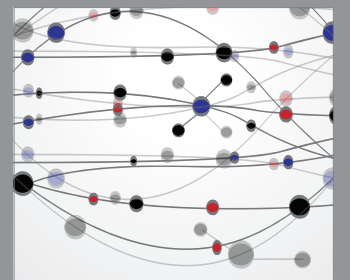

The Scientific World Journal
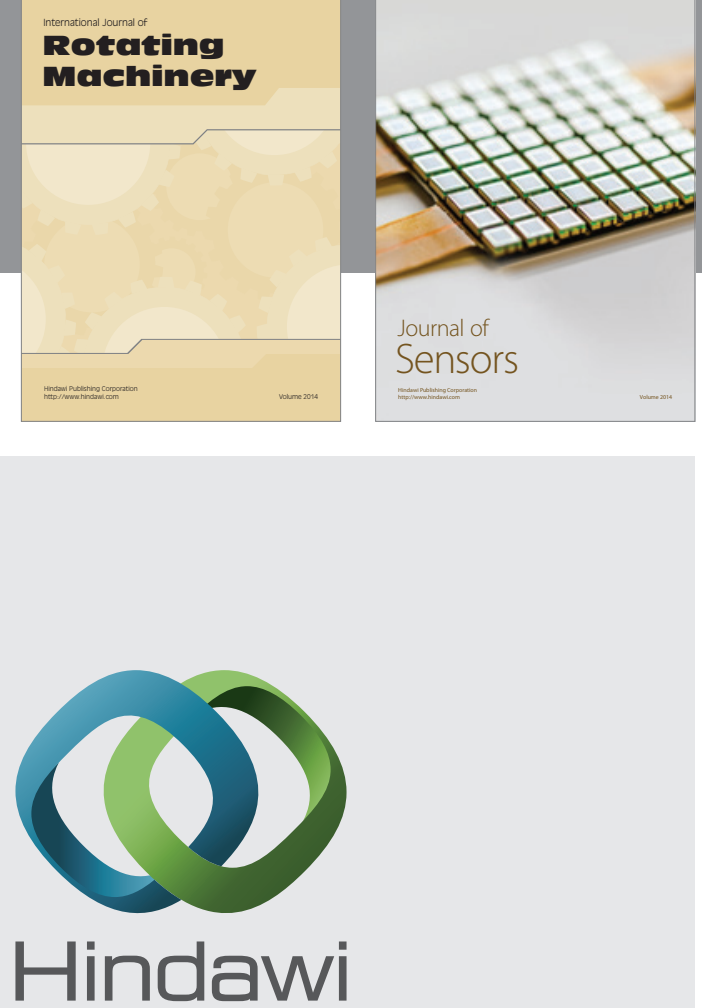

Submit your manuscripts at http://www.hindawi.com
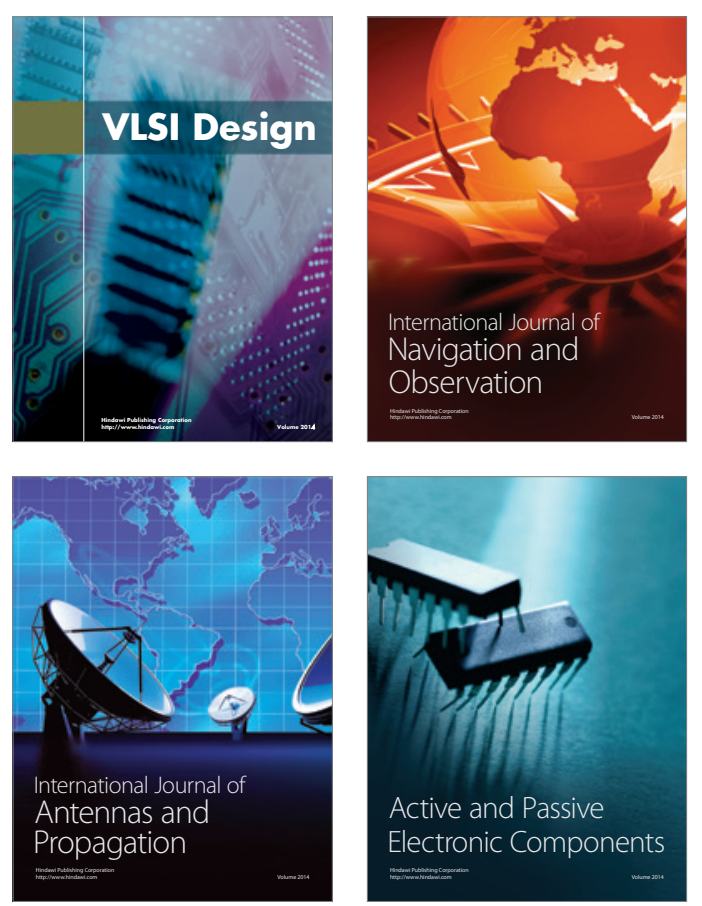
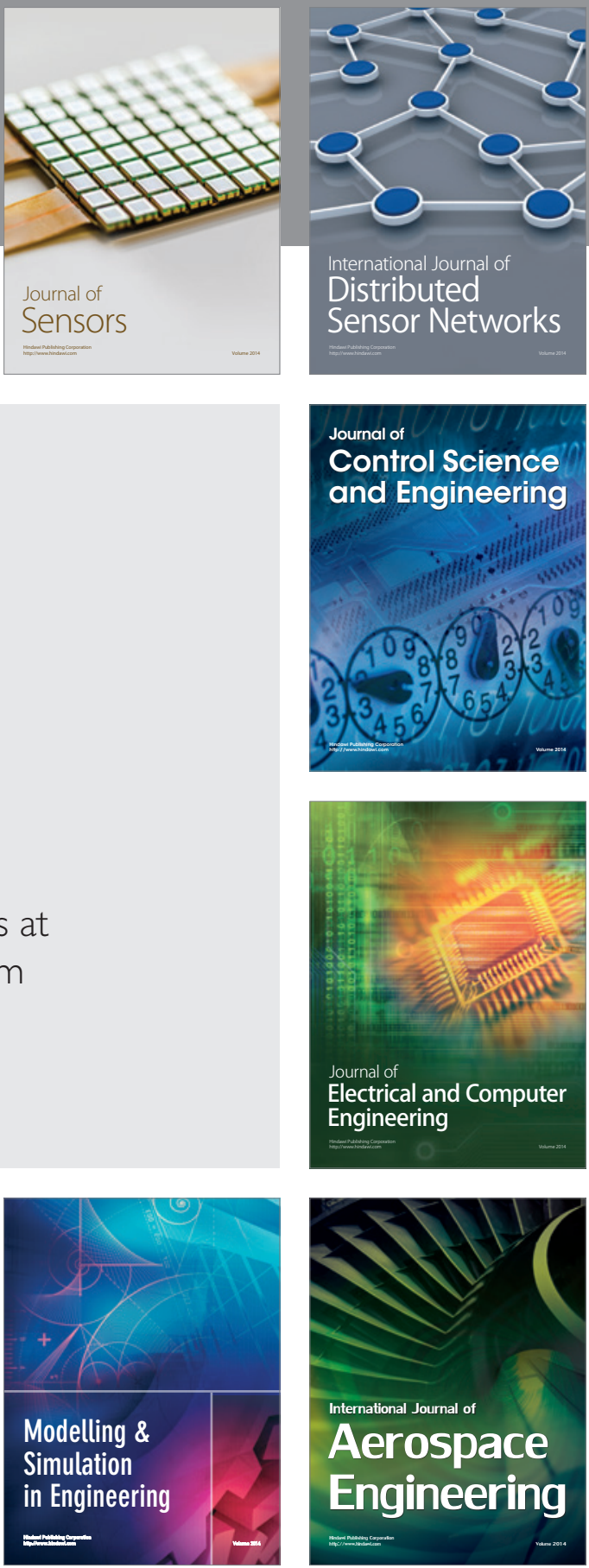

Journal of

Control Science

and Engineering
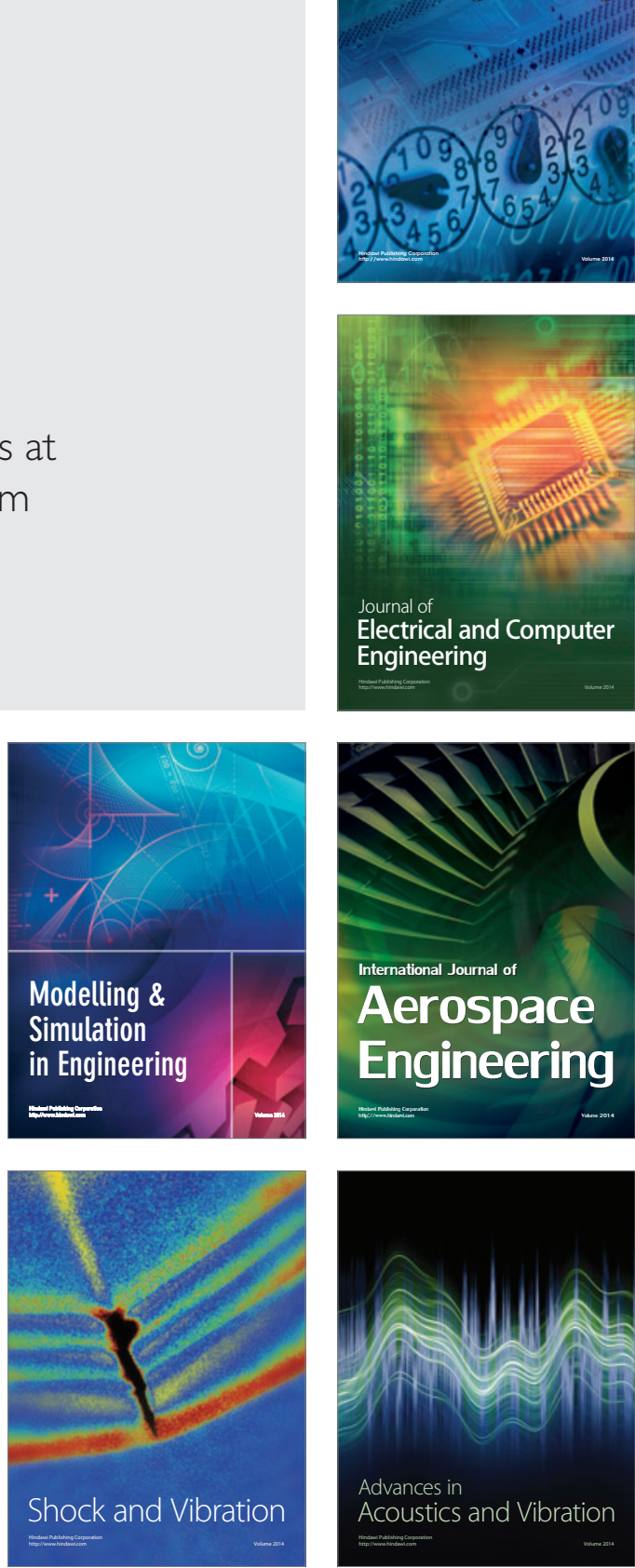